\title{
ADOLESCER NA CONTEMPORANEIDADE: UMA CRISE DENTRO DA CRISE
}

Humberto Moacir de Oliveira e Bruno Curcino Hanke

Humberto Moacir de

Oliveira

Universidade

Federal de Minas

Gerais (UFMG),

Mestre pelo

Programa de

Pós-Graduação em

Psicologia, Belo

Horizonte/MG,

Brasil.

Bruno Curcino Hanke

Universidade

RESUMO: Há tempos, a psicanálise tem demonstrado as crises que marcam o mundo contemporâneo. O lugar claudicante do pai, a inconsistência do Outro e o imperativo de gozo são marcas do discurso capitalista atual. Diante desse cenário, outra crise ganha espaço nas discussões sobre clínica e sociedade. Trata-se da experiência da puberdade e das séries de respostas que se reúnem em torno do que é chamado de crise da adolescência. O presente artigo se propõe a identificar as especificidades tanto da puberdade quanto Federal de Minas Gerais (UFMG), Doutorando do Programa de Pós-Graduação em Psicologia, Belo Horizonte/MG, Brasil. do momento histórico em que vivemos para assim colaborar com a discussão sobre o adolescer na sociedade contemporânea.

Palavras-chave: adolescência; puberdade; contemporaneidade; psicanálise.

ABSTRACT: Adolescent in contemporary: a crisis within the crisis. Psychoanalysis has long demonstrated the crises that mark the contemporary world. The halting place of the father, the inconsistency of the Other and the imperative of enjoyment are trademarks of today's capitalist discourse. Given this scenario, another crisis is gaining ground in discussions of clinical and society. This refers to the experience of puberty and the series of responses that come together around what is called the crisis of adolescence. In order to collaborate with the discussion of the adolescent in contemporary society, this article aims to identify the specificities of puberty and the historical moment in which we live.

Keywords: adolescence; puberty; contemporary; psychoanalysis.

DOI - http://dx.doi.org/10.1590/1809-44142017002001 


\section{INTRODUÇÃO}

Falar de adolescência na contemporaneidade exige alguns desafios bem instigantes ao psicanalista. O principal deles talvez seja pensar qual a leitura psicanalítica possível da adolescência, já que o objeto de estudo e tratamento da psicanálise é o sujeito do inconsciente, apresentado desde cedo por Freud como um sujeito sem idades. Outro desafio do tema é destacar quais seriam os efeitos da contemporaneidade no aparelho psíquico, novamente levando em conta a relação do Outro contemporâneo com o sujeito do inconsciente. Enfim, o grande desafio parece ser abordar o tema da adolescência na contemporaneidade mantendo-se fiel à epistemologia da psicanálise, que tem como ética a ética do sujeito do inconsciente, portanto, um sujeito sem predicados.

No entanto, o que parece um grande desafio mostra-se um pouco menos penoso quando descobrimos que, já em Freud, estão os primeiros movimentos para a psicanálise desembaraçar-se dessas tramas. Afinal, Freud, por mais fiel que fosse às suas ideias, e talvez por isso mesmo, nunca se mostrou um teórico abstrato demais a ponto de não levar em conta o que acontece ao redor do sujeito e mesmo no decorrer de sua constituição. Freud falou tanto de infância, puberdade e vida adulta quanto de como a guerra, a religião, a arte e outros acontecimentos de sua época impactavam o psiquismo humano. Entender esses dois aspectos, dos tempos de constituição do sujeito e dos efeitos da cultura sobre o aparelho psíquico, sem desviar do sujeito do inconsciente, é trabalho fundamental ao psicanalista que deseja compreender as especificidades da adolescência nos dias de hoje.

É nesse sentido que o presente artigo é apresentado como proposta de contribuição ao tema. O primeiro passo a seguir é apresentar a adolescência como resposta sintomática para um tempo específico da sexualidade, a saber, a puberdade. A ideia é discorrer sobre esse aspecto para que se possa entender melhor qual o desafio psíquico que esse momento de despertar da sexualidade provoca no sujeito chamado adolescente.

Feito isso, será necessário ainda entender a dinâmica do mundo contemporâneo destacando o declínio da figura paterna e as transformações das exigências superegoicas como aspectos que dificultam ainda mais a experiência de subjetivação que ocorre na adolescência. Pois, se a imago do pai, enquanto representante da lei e organizador das normas, ajudava o adolescente a encontrar alguma resposta às perguntas lançadas pela puberdade (ainda que algumas dessas respostas buscassem contrariar ou atacar o pai), atualmente essas respostas contam cada vez menos com a ajuda do pai, o que explica o aumento de sintomas que denunciam uma separação do Outro, como a toxicomania, o suicídio ou a depressão. Aliada a esse aspecto de declínio da imago paterna, a figura superegoica de nossa época, que exige o gozo do consumo, também traz 
dificuldades a esse processo de subjetivação da adolescência, uma vez que favorece, como resposta à puberdade, o oferecimento do corpo em detrimento de qualquer ideal; o que, em outras épocas, talvez ajudasse a modular o gozo que os sintomas contemporâneos tanto exacerbam.

Ambos os aspectos devem ser tratados com bastante cautela, tanto para não supervalorizarmos a adolescência, aproximando-a, por exemplo, da delinquência, tanto para não cairmos em uma nostalgia, acreditando que, em outras épocas, a adolescência era muito mais tranquila. Não podemos, na psicanálise, tratar esses assuntos com juízos de valores. Não é o caso de julgar se nossa época é pior ou melhor do que as outras, nem se o adolescente é mais ou menos aborrecedor que uma criança ou um adulto. À psicanálise, cabe apenas perceber as especificidades tanto do momento histórico quanto do momento constitucional do sujeito para, a partir delas, pensar o seu trabalho clínico dentro e/ou fora dos consultórios. É em busca dessas especificidades que o presente trabalho ruma.

\section{ADOLESCÊNCIA, SINTOMA DA PUBERDADE}

O título desse subitem faz referência direta ao artigo de mesmo nome do psicanalista Alexandre Stevens (2004). Em seu texto, como denuncia o próprio título, Stevens deixa clara sua opção de tratar puberdade como termo mais fundamental e pertinente à psicanálise do que adolescência, sendo esta uma resposta à puberdade. Para o autor, adolescência é "um termo sociológico que, sob uma suposta base biológica, tornou-se de uso psicológico” (STEVENS, 2004, p. 27). Também na obra de Freud encontramos uma predileção pelo uso do termo puberdade e quase nenhuma referência à adolescência.

Mas antes de abordarmos a distinção e a relação entre puberdade e adolescência, é preciso inicialmente definir o que a psicanálise tenta abarcar com esses termos, pois é incompatível com a ideia freudiana propormos que esses nomes deem conta de um período do desenvolvimento humano que cessa com a chegada da vida adulta. Por várias vezes, Freud demonstrou que o inconsciente não pode ser apreendido em termos de idade cronológica. Desde seus estudos sobre o sonho até o final de sua obra, Freud não cansou de comparar o inconsciente com o funcionamento do psiquismo infantil ou dos povos primitivos. Isso demonstra que, mesmo quando Freud fala de uma fase do desenvolvimento humano, qualquer que seja ela, ele não está se referindo a um acontecimento natural com previsão para concluir. Pelo contrário, o que Freud sempre ressaltou foi que uma das principais dificuldades do aparelho psíquico é abandonar um modelo de funcionamento em benefício de outro. Isso indica que sempre há um resto insuperável no psiquismo humano que não passa com o avançar dos 
anos. Um resto de infância, sim, mas, por que não dizer também, um resto de adolescência?

Isso faz vacilar o sentido da idade cronológica em psicanálise. Um adulto pode ter os mesmos medos que uma criança e, ao atender um idoso, o psicanalista pode encontrar as mesmas fantasias que o sujeito tinha em sua adolescência. Nesse sentido, o sujeito, tal como apreendido na psicanálise, não tem idades. O sujeito não é nem um corpo que, com o passar dos anos, sofre mutações naturais filogeneticamente programadas nem a representação social que os anos computados em sua carteira de identidade provam. Para ser mais exato, o sujeito trabalhado por Freud está entre a pulsão, que tem fonte corporal, mas não é corpo, e a representação, que provem do campo do Outro, mas que nunca é apreendida por ele totalmente.

Lacan definiu bem essa condição do sujeito ao escrevê-lo com o S barrado (\$). Se o S na obra lacaniana representa o significante, a barra representa a falta. O sujeito seria então um significante que escapa à cadeia significante; e escapa, portanto, a qualquer representação. Pois, sendo o sujeito representado por um significante e tendo o significante seu valor na diferença que ele sustenta em relação a outros significantes da cadeia, o sujeito se encontrará sempre nesse intervalo, não sendo nem o significante que o representa (S1) nem o significante que a esse faz diferença (S2). Ou seja, para Lacan, o sujeito é sempre o que está entre um significante e outro, nunca podendo ser representado integralmente por nenhum deles: "O sujeito não é outra coisa - quer ele tenha ou não consciência de que significante ele é efeito - senão o que desliza numa cadeia de significantes" (LACAN, 1972-73/1985, p. 68). Por isso, o sujeito, por definição, escapa às identificações objetivas do laço social, inclusive às identificações referentes à sua idade.

No entanto, isso não implica que a psicanálise desconsidere os tempos do sujeito, tampouco que o psicanalista não veja os efeitos que as representações e identificações sociais apresentam no inconsciente. Assim, podemos pensar, como alerta a psicanalista argentina Alba Flesler (2012), que, se o sujeito não tem idades, ele apresenta tempos. Embora a ideia de tempo lógico seja desenvolvida por Lacan (1945/1998), algo semelhante, mas não idêntico, também pode ser encontrado em Freud em sua interpretação da sexualidade humana. Freud (1905/1996), ao distinguir, em seus ensaios sobre a sexualidade, uma organização infantil seguida de um período de latência e, posteriormente, da puberdade, parece menos fixar fases de desenvolvimento a serem cumpridas cronologicamente do que tempos da constituição da sexualidade. Cada um desses tempos (o instante de ver do primeiro despertar sexual, o tempo para compreender do período de latência e o momento de concluir da puberdade), embora sejam necessários para pensar a lógica da constituição da sexualidade humana, não são fatos empíricos capazes 
de serem relacionados de modo cronológico e imediato à vida do sujeito, por isso não têm um momento preciso de início e fim previamente determinado.

É sob esse prisma que a puberdade chega até a pena de Freud. Para o psicanalista vienense, a puberdade representava, antes de qualquer fase ou idade cronológica, o tempo posterior ao período de latência. Se, no período anterior à latência, Freud denunciava o primeiro despertar da sexualidade, a latência seria o momento em que essa sexualidade que se despertou nos primeiros anos de vida adormeceria. É desnecessário dizer o quanto Freud defendeu que esse adormecer da sexualidade no período de latência não representa uma anulação de seus efeitos, senão um arrefecimento, de modo algum total. E é no período de latência que Freud supõe iniciar os principais impactos da cultura sobre o sujeito: recalque, sublimação, formação de caráter, fantasia e os primeiros arranjos sintomáticos. A puberdade aparece então como o momento em que ocorre um segundo despertar da sexualidade, logo após esse período de arrefecimento ou suposto adormecimento.

Não por acaso, será em torno da teatralização deste despertar da sexualidade que vai girar uma das poucas referências lacanianas sobre o tema da adolescência. Ao prefaciar a peça O despertar da primavera, de Wedekind (1973), Lacan (1974/2003) destaca essa dimensão do despertar da sexualidade, dizendo que a sexualidade não faz sentido, ela faz furo no real. A ocorrência do despertar dos personagens adolescentes da peça é, para Lacan, um encontro com o real, principalmente com o real do sexo. Real aqui, no sentido lacaniano do termo, enquanto o que carece de simbolização ou imagem. Real que, como lembra Stevens (2004), não pode ser resumido ao aumento hormonal que exige a expulsão dos líquidos sexuais, o que não provoca nenhuma crise relevante em outros animas. O real aqui deve ser entendido, principalmente, como falha do simbólico e do imaginário. Pois, se o primeiro despertar da sexualidade foi procedido de um tempo de latência em que o sujeito encontrou, ainda que precariamente ou fantasiosamente, um arranjo simbólico e imaginário para suas pulsões parciais ou para a sua perversão polimorfa, a puberdade é o momento em que esse arranjo falha.

O campo do Outro assinalado por Lacan (1960/1998) como tesouro dos significantes, assim como a figura do pai, que como representante da lei ordena esse campo simbólico ao denunciar a falta do Outro exerce um papel fundamental no período de latência. A puberdade, ao revivificar o Édipo, como alerta Freud (1920/1996), demanda a reatualização das escolhas feitas na primeira infância e no período de latência; escolhas tanto de objeto quanto de posição em relação à sexuação. Ao reatualizar essas escolhas, o sujeito percebe que não mais pode contar com o Outro, nem com o pai, nem com as fantasias infantis e nem mesmo com a imagem do próprio corpo que está em abundante metamorfose. Imaginário e Simbólico falham; o real aparece. 
Essa é a principal ideia aqui defendida para falar de puberdade: a puberdade é o momento de encontro com o real porque o Outro, tesouro do significante e por isso também provedor de sentido, falha, assim como também falham a fantasia, o pai e as identificações. Diante desse quadro, o sujeito questiona os sentidos do mundo, apela e ataca os pais, vive severas crises de identidade, passa ao ato, rivaliza com gerações mais antigas, busca identificações fora do lar, experimenta as ambiguidades das escolhas objetais e da posição diante da sexualidade. Mas tudo isso que aparece como figuras do que a mídia chama de crise adolescente são respostas à puberdade, pelo menos se entendermos puberdade como um momento de encontro com o real. É nesse sentido que a adolescência se apresenta como uma série de respostas sintomáticas ao encontro com o real promovido pela puberdade.

Toda essa formulação vai ao encontro da proposta da psicanálise de pensar o sintoma sempre como uma resposta ao que Lacan (1972-73/1985) chamou de não relação sexual. Miller e Laurent (2005) lembram bem que, quando Lacan se refere à inexistência da relação sexual, é da pulsão que se trata. Dizer que não existe relação sexual é dizer que a pulsão não encontra no campo do Outro nenhuma acomodação possível ou proporcional à sua exigência. O que Lacan denuncia, obviamente, não é que não exista o ato sexual, mas que há uma disjunção entre a pulsão e o campo do Outro, mesmo quando o ato sexual acontece. A pulsão é estranha ao Outro ao mesmo tempo em que ela busca no Outro o objeto de sua satisfação. Sabemos desde Freud que esse objeto é para sempre perdido, ou seja, o sujeito não encontra esse objeto no Outro - nem no corpo de seu parceiro, nem na linguagem de seu país, nem na cultura de seu mundo. A puberdade, ao provocar novamente o despertar da sexualidade, exigindo a reatualização das escolhas sexuais, coloca o adolescente diante dessa impossibilidade de encontrar um destino para sua pulsão no campo do Outro, que inclui o pequeno outro, ou seja, seu semelhante, mas também toda a cultura, o mundo em que vive etc. A teoria biológica dos instintos animais nos faz supor que, entre os animais, há um saber fazer com a sexualidade que não existe entre os humanos. Como ressalta Stevens (2004), falta ao ser humano um saber no real sobre o que complementa os sexos. Na falta desse saber no real, o sujeito busca um saber no Outro. Mas esse saber falha, e é a essa falha do saber que o adolescente responde.

Entretanto, jamais podemos supor que esse encontro com a falta de saber no real seja algo exclusivo da adolescência. E aqui talvez valha a pena fazer a mesma pergunta que Freud (1917/1996) se fez ao estudar os melancólicos. Diante das queixas dos melancólicos que se recriminavam por não valerem nada, por serem vis ou pela falta de sentido da vida, Freud se pergunta pelo motivo dessas pessoas só conseguirem enxergar essas verdades depois da enfermidade? O que Freud revela é que somos todos vis e que a vida de todos é sem sentido, 
mas os melancólicos se detêm diante disso, enquanto outros preferem não lidar com isso. O adolescente também parece carregar essa indignação, por vezes melancólica, com os arranjos e sentidos do mundo. Em recente visita ao Brasil, o Papa Francisco disse em reportagem que não lhe agrada um jovem que não se manifesta. Até que ponto o Santo Padre realmente deseja uma revolução é algo que podemos muito questionar, mas ele denuncia uma relação entre juventude e mudanças revolucionárias que vale a pena ser escutada. O jovem apelidado pela mídia de "aborrecente" é exatamente o que se indigna com o saber do Outro, que questiona o saber dos pais e que, confrontando com antigas gerações, provoca tanto os aborrecimentos familiares quanto as transformações mais importantes de um país.

Aqui vale uma reflexão um pouco mais detalhada, para não concordarmos rápido demais com a caricatura do adolescente apresentada pela mídia. Dizer que o encontro com a impossibilidade da relação sexual, com o fracasso do Outro e com a tarefa de desligar-se dos pais são eventos que marcam a puberdade, não pode querer dizer que as respostas serão sempre de enfrentamento do Outro ou revolucionárias. É preciso entender que os sintomas em psicanálise são sempre singulares. E as respostas a esse encontro com o real serão também muito diversas, agradem ou não ao Papa. Por mais que a mídia ou os pais vejam nos sintomas de desafio ao Outro um maior incômodo ou maior possibilidade de mudança, temos que tomar cuidado para não considerarmos esse tipo de sintoma mais grave apenas por ser mais tumultuador ou transformador à ordem do mundo. Muitas vezes, a resposta sintomática ocupa exatamente o lugar oposto, de tentar recuperar no Outro a suposta completude do saber perdida com o encontro com o real. Jovens que se dedicam a uma alienação ainda maior no campo do Outro, justamente por não quererem crer no real para o qual foram despertados. Encontramos, nessa situação, jovens que se dedicam aos estudos tentando recuperar desesperadamente o saber que lhes foi revelado insuficiente ou que tentam cumprir com todas as exigências impossíveis do Outro, desde o padrão de beleza corporal até o consumo exagerado ordenado pela mídia. Esses são os jovens que o Papa disse não gostar, embora, por muito tempo, a Igreja lutou exatamente para que todos fossem como esses jovens. O fato desses sintomas de alienação no campo do Outro supostamente causarem menos barulho na família e menos mudanças na sociedade não deve ser considerado como sinal de menor gravidade do sintoma. Os casos de adolescentes que se definham para ter o corpo supostamente exigido pela mídia nos mostra que alienar-se no Outro não é uma saída necessariamente melhor do que a ele se opor.

No entanto, a esse quadro de respostas sintomáticas em que até agora destacamos a busca pelo confronto com o Outro e a alienação a esse mesmo Outro podemos acrescentar uma resposta que, essa sim, se revela mais grave que as 
demais por ser uma separação muito mais radical do campo do Outro do que tudo citado acima. Refiro-me aqui ao que Lacan (1962-1963/2005) chamou de passagem ao ato. Diante do fracasso da fantasia, o sujeito pode escolher saltar para fora da cadeia significante, dela se separando radicalmente, como acontece nos atos suicidas. É o caso de Moritz, um dos personagens principais de $\mathrm{O}$ despertar da primavera. Seus pais depositam em sua formação escolar a esperança de um futuro melhor para toda a família. Moritz tenta a todo custo cumprir com essa exigência, alienando-se no desejo dos pais. Mas, diante de seu fracasso, ele salta para fora do campo do Outro, ainda que para isso sacrifique a própria existência. Sonia Alberti (1999), para quem Moritz é um psicótico, destaca bem a diferença do suicídio do personagem de Wedekind e de outras tentativas de suicídio que, ainda que graves, buscam enviar uma mensagem ao Outro. É o caso de Dora, que escreve um bilhete para os pais prenunciando uma possível tentativa de suicídio que sequer chega a ocorrer. Em Moritz, não há mensagem, há um salto para fora do desejo dos pais e, por fim, da própria cadeia significante.

Enfim, os sintomas são vários e devem sempre ser tratados caso a caso. No entanto, ainda assim é possível delinear algumas séries de respostas que vão desde o confronto com o Outro (através de indisciplina, delinquência, revolução, conflito de gerações) até a alienação ao Outro (através do estresse, ansiedade, obsessão pelo estudo, consumo, sacrifícios em prol da beleza); além da possibilidade de tentativa de separação radical do Outro (através da passagem ao ato, suicídio ou homicídio). Outras séries de sintomas poderiam ser pensadas, mas, por enquanto, vamos nos deter em dizer que todas essas respostas de alienação, separação e confrontação (que não deixa de ser uma tentativa de separação, quem sabe uma tentativa alienada de separação) atendem ao mesmo problema: o encontro, na puberdade, com a impossibilidade da relação sexual, com a disjunção entre a pulsão e o Outro ou, em outras palavras, com o real.

\section{O OUTRO CONTEMPORÂNEO}

Tendo ressaltado os desafios que a experiência da puberdade impõe ao processo de subjetivação do adolescente, e algumas séries de respostas possíveis a esses desafios, é hora de pensar as especificidades que nosso momento histórico apresenta a esse tempo de despertar para o real. Novamente, encontramos alguns desafios que a ética da psicanálise nos impõe, pois é preciso, mais do que fazer uma análise sociológica de como o mundo contemporâneo funciona (o que por si já demandaria um grande esforço), pensar em como esse funcionamento do mundo atual incide no sujeito do inconsciente. Em Psicologia de grupo e a análise do ego, Freud (1921/1996) já havia destacado a influência recíproca que existe entre o sujeito e o mundo que o cerca. O psicanalista afirma, por exemplo, não haver 
motivos para contrastarmos radicalmente a "psicologia individual" e a "psicologia social", uma vez que um estudo de grupos não pode negligenciar o fato de que todo grupo humano é formado por um encontro de pessoas, da mesma forma que uma análise individual não deve desprezar o fato de todo ser humano sofrer consequências das relações que mantém com os outros seres humanos e com o mundo que o cerca.

Lacan (1960/1998) irá aproximar ainda mais essa relação do sujeito com aquilo que lhe é alteridade quando propõe, como um dos nomes do inconsciente, o Outro. Portanto, em Lacan, a presença do inconsciente situa-se no lugar do Outro enquanto tesouro do significante, depósito do material que o sujeito recebe do que lhe é estranho ou externo. O próprio sujeito, como foi visto acima, passa a ser definido por Lacan como efeito desse Outro, já que o significante que o representa para outro significante vem desse campo.

Assim é que, em psicanálise, sujeito e Outro se fundem de certa maneira que podemos afirmar que tudo o que é exterior ao sujeito também lhe é bastante pertencente. A relação que temos aqui é semelhante ao que Lacan (19621963/2005) salientou acontecer na banda de Moebius, onde uma fita, torcida de maneira peculiar, coincide duas superfícies, assim misturando o interior e o exterior e quebrando com a lógica da topologia da esfera onde se tem uma separação clara entre as superfícies interna e externa. Assim, o sujeito não está imune aos acontecimentos da palavra que o representa, do corpo que nele pulsa, do mundo que o cerca, da política que o comanda, da ciência que o define e de toda a cultura que o afeta e o produz. No entanto, o lugar do Outro permanece sendo o mesmo: morada dos significantes que se articulam em cadeias ao mesmo tempo em que sofrem e causam efeitos do e no real. O lugar do Outro permanece sendo sempre o lugar para onde o sujeito dirige suas questões. Porém, por ser morada dos significantes, ele está vivo tal como podemos dizer que a língua é viva, ou seja, está em constante modificação e construção, sofrendo alterações que afetam os discursos dominantes da cultura e influenciam os modos do sujeito se posicionar frente à castração, ao desejo, ao sexo, à lei e à angústia. Em outras palavras, o sujeito não existe sem o Outro e o Outro se estende até a cultura. Por isso, não podemos encarar como sendo a mesma coisa adolescer na Viena de Freud, na Alemanha de Wedekind ou no mundo globalizado de hoje. O mundo sofreu mudanças desde os tempos de Freud, e a psicanálise deve saber apreender essas mudanças para que permaneça viva. É hora, então, de salientar quais as principais especificidades de nosso tempo que incidem sobre a experiência da adolescência.

São várias as mudanças que ocorreram desde a invenção da psicanálise até os dias de hoje, e a própria teoria psicanalítica colaborou com algumas delas, ao passo que foram outras tantas que colaboraram com o avanço da psicanálise. 
Por vezes, Freud arriscou alguns palpites para o que seria o mundo depois dele. Podemos nos servir de algumas dessas previsões freudianas para compreender as mudanças que ocorreram na sociedade contemporânea. É o caso da sugestão dada aos leitores de sua época para que eles esperassem do mundo futuro um despertar para a ciência que superasse a religião, a tal ponto dessa última fracassar. É fato que estamos longe de presenciar o fracasso da religião, como bem ressaltou Lacan (1960-1974/2005) em uma de suas entrevistas em Roma. Porém, não parece ser tão equivocado o lugar que Freud reservou à ciência no futuro. Apostando em uma correlação entre a filogênese e a ontogênese, Freud (1927/1996) acreditava que cada ser humano repetia o progresso da civilização, o que o fez equivaler o pensamento infantil ao modo de funcionamento psíquico dos povos primitivos e a sugerir um desenvolvimento progressivo da humanidade de uma visão do mundo animista para uma científica, passando, nesse intervalo, por uma visão de mundo religiosa. Assim, a própria época em que Freud viveu já teria uma visão de mundo científica despertada principalmente por Descartes e Galileu, considerados por Lacan (1965/1998) os pais da ciência moderna. Segundo Freud, essa visão científica do mundo estaria em vias de superar a visão religiosa. Confirmando a hipótese freudiana, e a despeito do lugar importante que a religião ainda ocupa no mundo, a ciência avançou de modo a quase substituir o Deus religioso (pai, todo poderoso) pelo "deus" da razão. Se houve uma época em que toda a contingência era atribuída à vontade de Deus, hoje Deus divide lugar com as explicações científicas, quando não é superado por elas.

Por mais que a ciência hoje seja acusada de ocupar um lugar quase religioso, a ponto de suas supostas comprovações serem tomadas como verdade última por boa parte da população, não podemos dizer que essa substituição do Deus da religião pela razão não tenha consequências. É pouco dizer que tudo permanece o mesmo, apenas a ciência ocupando o lugar anteriormente ocupado por Deus. O próprio Freud nos ajuda a pensar essa substituição e a transformação proporcionada por ela. Quando diz que a religião é uma ilusão, pelo fato dela apresentar uma verdade que não pode ser questionada, Freud não é ingênuo para dizer que a ciência seja, em contraposição à ilusão, uma verdade. Se lermos corretamente o texto de Freud (1927/1996), veremos que, para ele, a ciência é um erro. Ou, melhor dizendo, uma sucessão de erros. A ciência não deixa de ser uma ilusão por ser uma realidade última, mas por permitir a verificação do erro e, de verificação em verificação, ir avançando seu conhecimento. Se o Deus da religião é onipotente e onisciente, o “deus" da ciência é um deus que erra. E se a ciência é chamada para ocupar o lugar do pai nos dias de hoje, então nos deparamos com um pai errante, que afirma que o ovo faz mal em uma semana e na outra nega o que anteriormente afirmou. Portanto, é preciso ressaltar que 
é bastante diferente que o lugar do pai seja ocupado pelo Deus da religião ou pela razão científica.

Enfim, a razão varreu a onipotência do pai. Isso é demonstrado no próprio seio familiar, onde é cada vez mais comum os pais pedirem auxílio à ciência, à psicologia, à pedagogia ou mesmo às estatísticas para educarem seus filhos. Muito cedo, Lacan se atinou para isso e, no final da década de 30 , chegou a afirmar que "um grande número de efeitos psicológicos parece-nos decorrer de um declínio social da imago paterna. Um declínio condicionado por se voltarem contra o indivíduo alguns efeitos extremos do progresso social" (LACAN, 1938/2003, p. 66-67). De lá para cá, não apenas o pai da religião tornou-se questionável e falho, mas a própria imagem do pai enquanto regulador do gozo e legislador das normas assumiu um aspecto claudicante, falho, evasivo. As grandes figuras substitutivas do pai, como os professores, governantes ou patrões, foram perdendo aos poucos sua autoridade ao passo que essa autoridade foi sendo distribuída de maneira dispersa no saber científico. É cada vez mais comum um governante, mesmo o presidente de um país, revelar sua falta de saber denunciando a quantidade de variáveis de que depende seu governo. Essas variáveis são contabilizadas pelo saber da ciência. Da mesma forma, um professor é cada vez mais questionado em sala de aula a partir de informações colhidas momentaneamente na internet, um produto direto da ciência tecnológica. O patrão é acusado de assédio moral e teme os processos que podem prejudicá-lo. Nas empresas, é possível perceber uma substituição da palavra chefe pela palavra líder, indicando que o ocupante do cargo em questão não é uma exceção que goza de todos os privilégios e faz o que quer, mas um ser humano falho, disposto a participar do processo de construção das ideias e das tarefas; enfim, muito mais próximo de um irmão mais velho do que de um pai. Isso é o que a psicanálise entende por declínio da paternidade e Stevens (2004) faz muito bem em dizer que não cabe ao psicanalista dizer se assim é melhor ou pior, ou propor um retorno da virilidade do pai. Cabe ao psicanalista compreender o seu tempo e atualizar sua clínica sem se afastar de sua ética.

Associado ao declínio da paternidade, encontramos outro efeito do progresso científico que parece também apresentar novos desafios ao sujeito adolescente de hoje. As conquistas tecnológicas alcançadas pela ciência permitiram que o capitalismo sofresse algumas alterações significativas. O filósofo Vladimir Safatle (2005) chama a atenção para uma modificação que chega a ocorrer no próprio supereu, instância psíquica formulada por Freud para dar conta exatamente da introjeção dos valores de uma época no psiquismo humano. Para Safatle, ainda que a visão científica do mundo já fosse de certo modo presente nos tempos de Freud, a sociedade de produção persistia alimentando o supereu repressor típico 
da visão religiosa. Recorrendo à sociologia de Max Weber, Safatle nos revela que a marca do capitalismo como sociedade de produção não era o gozo de bens e serviços como encontramos atualmente, mas, mais precisamente, o acúmulo de capital daqueles que: “(...) não retiram nada de sua riqueza para si mesmos, a não ser a sensação irracional de haver 'cumprido' devidamente sua tarefa”" (WEBER apud SAFATLE, 2005, p. 124). O acúmulo de capital demanda uma renúncia e a sociedade de produção é, então, marcada por um supereu rigoroso que preza pela renúncia ao gozo, ou, o que pode ser até mais preciso, um supereu que demanda um gozo na renúncia e no acúmulo; portanto, um gozo no ideal.

Com o avanço da ciência, que possibilitou um enorme desenvolvimento tecnológico e, por sua vez, um considerável aumento da produtividade, foi possível que mais sujeitos estivessem distantes do vínculo direto com o processo de produção. Abriu-se um campo maior para o setor terciário, que diz respeito aos bens e serviços. Essa expansão do consumo de bens e serviços fez com que a tônica, que antes caía na acumulação de dinheiro e no gozo do ideal da posse, passasse a cair no dispêndio, no consumo e no gozo de objetos ofertados pela ciência e tecnologia. O exemplo cotidiano que temos dessa reviravolta do acúmulo e da produção para o gozo e o consumo é o cartão de crédito. Com o cartão de crédito, o gozo vem antes do acúmulo de capital, e antes também da renúncia pulsional exigida pelo "supereu freudiano". Para Safatle, essa nova figura do supereu, que poderia ser chamada de "supereu lacaniano", está menos vinculada à repressão das moções pulsionais do que à assunção dos fantasmas: "Não mais a repressão ao gozo, mas o gozo como imperativo. Daí porque ele [Lacan] nos lembra que o verdadeiro imperativo do supereu na contemporaneidade é: 'Goza!', ou seja, o gozo transformado em uma obrigação" (SAFATLE, 2005, p. 127).

O problema dessa modificação no processo de socialização, que comporta um imperativo de gozo no lugar da renúncia, é que essa ordem ("Goza!”) é impossível de ser satisfeita. O supereu não diminuiu sua pressão nem sua insensatez, ele apenas trocou sua exigência. Se, antes, sua exigência era "não se satisfaça", o que era igualmente impossível, pois o sujeito se satisfazia no sintoma, agora ele ordena o gozo, mas nada diz sobre como gozar. Ou melhor, diz de tantas formas que é o mesmo que não dissesse.

A partir das discussões de Miller e Laurent (2005) sobre o mesmo tema, podemos dizer que o supereu freudiano é marca de uma época em que o ideal era maior que o gozo $(\mathrm{I}>\mathrm{a})$. Isso quer dizer que o circuito do gozo passava pelo Outro social que, através dos ideais da época, modulava a satisfação. É o que Weber salienta quando diz que o homem da sociedade de produção não retirava nada de sua riqueza para si mesmo a não ser a sensação de tarefa cumprida (o ideal da época). Atualmente, vivemos em uma época em que o ideal é menor do que o gozo $(\mathrm{I}<\mathrm{a})$, o que significa que o modo de gozo contemporâneo não 
é mais organizado pelo ideal e funciona em um estatuto que Miller e Laurent denominam de autista.

\section{ADOLESCER NA CONTEMPORANEIDADE}

É diante desse cenário, de queda da função paterna e de um supereu que ordena o gozo para além de qualquer ideal, é que os jovens de hoje devem experimentar sua puberdade. Se uma das tarefas da puberdade que podemos extrair do texto freudiano é desligar-se do pai, podemos mesmo nos questionar se a própria sociedade contemporânea não é convidada a uma tarefa semelhante. Na proposta de Freud, de que o desenvolvimento filogenético e ontogenético se coincidem, podemos dizer que os povos primitivos estão tão próximos do psiquismo infantil como a sociedade contemporânea está da adolescência. Crise da imago paterna, crise dos ideais, crise do Outro, enfim, muito do que afirmamos caracterizar a adolescência também caracteriza o mundo em que atualmente vivemos.

O que essas análises do mundo contemporâneo nos revelam é que o adolescente pode atualmente contar ainda menos com o Outro. Freud (1914), ao escrever sobre a psicologia do escolar em texto que aborda sua própria juventude, diz que passou todo o período do ginásio esboçando em voz baixa a tarefa que iria se propor no futuro. No fim de seus estudos, ele pôde transpor essa tarefa para o papel, escrevendo em uma dissertação seu desejo de legar alguma contribuição ao saber humano. Para Hugo Freda (1996), a tarefa a que Freud se refere é a de inscrição de um desejo no campo do Outro. Tarefa que Freda atribui a todo adolescente, pois desligar-se da influência dos pais é de certo modo buscar essa inscrição para além do lar. Para o autor, há uma grande distinção entre a identificação infantil ao adulto por exemplo, pela via de querer exercer a atividade profissional do Outro (ser policial como o tio, advogado como o pai, médico como o avô etc.) e a inscrição de um desejo próprio no campo do Outro, tarefa mais tipicamente adolescente do que infantil.

Se o Outro contemporâneo é tão débil quanto propomos acima, ou mesmo se ele não existe, como chega a sugerir Miller e Laurent (2005), então a tarefa do adolescente se torna ainda mais complicada. Houve uma época em que os adolescentes, ao desligarem-se das influências dos pais, encontravam fora do lar uma oferta de grupos de exceção com os quais buscavam se identificar. Punks, hippies, roqueiros, eram nomes que sustentavam um valor representativo mais ou menos sólido que os jovens se aderiam algumas vezes até pelo resto da vida. Atualmente, valores continuam sendo ofertados, mas com uma dispersão tão grande e uma velocidade tão absurda que o jovem não parece mais se iludir muito com eles. O grito presente na música de Frejat e Cazuza (1988) no fim dos anos 80 dá uma ideia do que os jovens viveriam com cada vez mais inten- 
sidade. Depois de dizer que seus heróis morreram de overdose, Cazuza clama: "Ideologia, eu quero uma pra viver".

Para Miller (2005), o que mudou é que, anteriormente, os sujeitos recebiam o valor representativo (o significante mestre, S1) advindo do campo do Outro e, atualmente, ainda segundo o autor, os sujeitos elaboram seus próprios S1, sem avaliação do Outro. Para Safatle, trata-se de uma desvinculação entre o imperativo de gozo e os conteúdos normativos privilegiados na sociedade, o que é bastante próprio do conceito lacaniano de supereu que diz “Goze!”, mas não indica a norma, ou seja, demanda o gozo de qualquer maneira — ou de todas as maneiras: "Os sujeitos não são mais chamados a se identificarem com tipos ideais construídos a partir de identidades fixas e determinadas, o que exigiria engajamentos e uma certa ética da convicção” (SAFATLE, 2005, p. 132). O adolescente contemporâneo fica perdido entre a ordem superegoica do gozo e a abundância metamórfica das formas de gozar, o que não fixa nenhum S1, como diria Miller, nenhuma ideologia, como diria Cazuza, nenhum tipo ideal, como diria Safatle. Até mesmo porque a liquidez e fugacidade desses modos de gozo é parte essencial do discurso capitalista atual. Eis a tarefa do adolescente, e talvez não apenas do adolescente, de hoje: viver suas crises dentro das crises que seu mundo enfrenta.

\section{CONSIDERAÇÕES FINAIS}

Adolescer na contemporaneidade é adolescer sem a ideologia clamada por Cazuza em 1988. É adolescer diante de uma crise generalizada da figura paterna, é adolescer com a difícil tarefa de inscrever seu desejo no campo de um Outro cada vez mais falho. Isso implica mudanças na clínica psicanalítica desses jovens. Tornam-se cada vez mais comuns adolescentes que mantêm uma relação autista diante de seus aparelhos eletrônicos, ou que buscam um gozo que supostamente prescinda do outro, como na toxicomania, ou ainda uma recusa absoluta diante da demanda do Outro para que ele coma, como nos casos de anorexia. Cabe à psicanálise se reinventar diante desses casos e fazer o que Freud sempre fez muito bem: aprender com os sintomas de sua época para deles elaborar sua prática e teoria, fazendo coincidir pesquisa e tratamento. É o convite e o desafio que os adolescentes de hoje nos encaminham. 


\section{REFERÊNCIASS}

ALBERTI, S. Esse sujeito adolescente. Rio de Janeiro: Rios Ambiciosos, 1999. FREJAT e CAZUZA Ideologia. In: CAZUZA. Ideologia. Rio de Janeiro: Universal Music Group (UMG). CD. Faixa 1. 1988.

FLESLER, A. A psicanálise de crianças: e o lugar dos pais. Rio de Janeiro: Zahar, 2012.

FREDA, H. O Adolescente Freudiano. In: RIBEIRO, H. C.; POLO, V. (orgs.). Adolescência: o despertar. Rio de Janeiro: Contra Capa Livraria, 1996. FREUD, S. Algumas reflexões sobre a psicologia do escolar (1914). Rio de Janeiro: Imago, 1996. (Ed. standard brasileira das obras completas, 13). . A psicogênese de um caso de homossexualismo numa mulher (1920). Rio de Janeiro: Imago, 1996. (Ed. standard brasileira das obras completas, 18).

Luto e melancolia (1917 [1915]). Rio de Janeiro: Imago, 1996.

(Ed. standard brasileira das obras completas, 14).

O futuro de uma ilusão (1927). Rio de Janeiro: Imago, 1996.

(Ed. standard brasileira das obras completas, 21).

Psicologia de grupo e análise do eu (1921). Rio de Janeiro:

Imago, 1996. (Ed. standard brasileira das obras completas, 18).

Três ensaios sobre a teoria da sexualidade (1905). Rio de Janeiro:

Imago, 1996. (Ed. standard brasileira das obras completas, 7).

LACAN, J. A angústia (1962-1963). Rio de Janeiro: J. Zahar, 2005. (O seminário, 10). A ciência e a verdade (1965). In: Escritos. Rio de Janeiro:

J. Zahar, 1998.

Mais, ainda (1972-1973). Rio de Janeiro: J. Zahar, 1985. (O seminário, 20).

Os complexos familiares na formação do indivíduo (1938). In: Outros escritos. Rio de Janeiro: J. Zahar, 2003.

O tempo lógico e asserção de certeza antecipada (1945). In: Escritos. Rio de Janeiro: J. Zahar, 1998.

O triunfo da religião (1960-1974). Rio de Janeiro: J. Zahar, 2005.

Prefácio a O despertar da primavera (1974). In: Outros

escritos. Rio de Janeiro: J. Zahar, 2003.

Subversão do sujeito e dialética do desejo no inconsciente freudiano (1960). In: Escritos. Rio de Janeiro: J. Zahar, 1998.

MILLER, J.-A.; LAURENT, E. El Otro que no existe y sus comités de ética. Buenos Aires: Paidós, 2005.

MILLER, J.-A. Psicoanálisis y sociedade. Fuente Freudiana, 43/44 (marzo-octubre 2005), 7-30. Disponível em: <http://www.eol.org.ar/template. asp? Sec $=$ publicaciones $\&$ SubSec $=$ on_line $\&$ File $=$ on_line $/$ psicoanalisis_sociedad/miller-ja_lautilidad.html>. Acesso em: $13 \mathrm{dez} 2013$.

SAFATLE, V. Depois da culpabilidade: figuras do supereu na sociedade de consumo. In: DUNKER, C.; PRADO, L. A. (orgs.). Zizek crítico: política e psicanálise na era do multiculturalismo. São Paulo: Hacker, 2005. 
STEVENS, A. Adolescência, sintoma da puberdade. Curinga: clínica do contemporâneo. Belo Horizonte: EBP-MG. Nov. 2004, n. 20.

WEDEKIND, F. O despertar da primavera. Lisboa: Estampa; Seara Nova, 1973.

Humberto Moacir de Oliveira

beto7296@yahoo.com.br

Bruno Curcino Hanke

brunochanke@yahoo.com.br 